\title{
Towards circular agriculture - exploring insect waste streams as a crop and soil health promoter
}

\author{
K.L. Torgerson ${ }^{1 *}$, J.V. Meijering ${ }^{2}$, J. Sok ${ }^{1}$, M. Dicke ${ }^{3}$ and A.G.J.M. Oude Lansink ${ }^{1}$ \\ ${ }^{1}$ Business Economics, Wageningen University E Research, P.O. Box 8130, 6700 EW Wageningen, the Netherlands; \\ ${ }^{2}$ Mathematical and Statistical Methods - Biometris, Wageningen University E Research, P.O. Box 16, 6700 AA Wageningen, \\ the Netherlands; ${ }^{3}$ Laboratory of Entomology, Wageningen University E Research, P.O. Box 16, 6700 AA Wageningen, the \\ Netherlands; kirstin.foolen-torgerson@wur.nl
}

Received: 5 August 2020 / Accepted: 12 October 2020

(C) 2021 Wageningen Academic Publishers

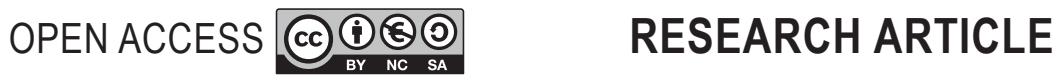

\begin{abstract}
Insects have tremendous potential for utilising the waste generated from other agricultural sectors to produce high value protein. The by-product of insect production, insect waste streams, can be recycled and repurposed for promoting the health of crops and soil as the chitin, present in the moulted skins, acts as a substrate for beneficial microbes that aid in plant protection. However, because insect waste streams are currently in the research and development phase, little information regarding its potential as a crop and soil health promoter is available. To address this information gap, this research explores experts' knowledge of the characteristics and application of insect waste streams as a crop and soil health promoter. To conduct this research, a two-step expert elicitation approach was used consisting of semi-structured interviews followed by a Delphi study. Interviews were conducted with six experts. Topics arising from the interviews that produced conflicting expert opinions were tested in the Delphi study. Fourteen experts participated in the Delphi study in an attempt to reach an agreement on these topics. The results of this research indicate that insect waste streams could be produced as a granulate-type compost, seed coating, or impregnated into a biodegradable seedling cup. To use insect waste streams, farmers should apply it next to the roots of each plant during the time of planting. Experts were unable to reach an agreement on some topics (e.g. dosage recommendations and expected yield changes). A brief discussion of insect waste streams' legal context is also provided. The results of this research contribute the first description of insect waste streams as a crop and soil health promoter. Such results serve as a tool to potentially aid in its uptake thus progressing towards circular agriculture.
\end{abstract}

Keywords: expert elicitation, delphi study, knowledge, innovation decision process

\section{Introduction}

The growing global human population and increasing wealth of those in the low-income group are creating a rising demand for protein consumption (Bodirsky et al., 2015; Steinfeld and FAO, 2006; Thornton, 2010). At the same time, recycling the by-products of one agricultural system for use in another (circular agriculture) and the quest for more sustainable food production and consumption are becoming higher priorities for policy makers (Rijksoverheid, 2019). Insects provide an attractive opportunity to contribute to both the aims of circular agriculture and the growing global protein demand (Chia et al., 2019; Van Huis, 2013). Thus, insect production is gaining traction as a form of minilivestock production. Such traction is evident by European insect producers' expectations of increasing investments from over $€ 350$ million in 2018 to over $€ 2$ billion by 2025 (IPIFF, 2019). The production of insects as a protein source has several advantages. First of all, insect production has demonstrated lower emissions of greenhouse gases and ammonia compared to conventional livestock production (Oonincx et al., 2010). Also, some insects are able to utilise the waste of other agricultural sectors and convert it into high value protein - a type of bioconversion (FAO, 2013; RDA, 2018). Insect production thus aligns with the United Nations' twelfth sustainable development goal for ensuring 
sustainable consumption and production patterns (United Nations, 2018) and contributes to circular agriculture.

Though insect production may utilise the waste of other sectors, the potential added value of its own generated by-product (i.e. insect manure or insect frass, moulted exoskeleton, and undigested feed) has been investigated primarily as a potential fertiliser application (Bortolini et al., 2020; Dulaurent et al., 2020; Houben et al., 2020; Poveda et al., 2019). However, there is increasing research attention to insect by-products having even greater potential as a crop and soil health promoter (Debode et al., 2016; Kebli and Sinaj, 2017; Quilliam et al., 2020; Temple et al., 2013; Vickerson et al., 2017). For example, research conducted by Bai (2015) showed that when the waste generated during insect production or insect waste streams (IWS) are integrated into the soil, bacilli colonisation increases by more than $15 \%$ after seven weeks. Many bacilli species are known to induce systemic plant resistance within its aboveground tissues and biological control against soilborne pathogens and below- and aboveground insect pests (Francesca et al., 2015; Gadhave and Gange, 2016; Gadhave et al., 2016; Lugtenberg and Kamilova, 2009; Sharma et al., 2013). Thus, IWS can be used to promote the health of crops and soil of arable farms, thereby also reducing the need for chemically-based plant protection products (PPP) such as chemical pesticides. Using IWS as an input for arable farms closes the loop of the insect production sector, making it a circular form of agricultural production.

For IWS to successfully penetrate the market, it must be an attractive crop and soil health promoter for farmers. One way to forecast IWS' attractiveness amongst farmers is by understanding the decision-making process farmers will undergo prior to making an adoption or rejection decision. The process is referred to as the innovation decision process (IDP). The IDP is 'the process through which an individual (or other decision-making unit) passes from gaining initial knowledge of an innovation, to forming an attitude towards the innovation, to making a decision to adopt or reject, to implementation of the new idea, and to confirmation of this decision' (Rogers, 2003).

Previous research has applied the IDP to farmers' uptake of various agricultural innovations. For example, Goldberger et al. (2013) explored farmers' adoption decisions for biodegradable plastic mulches in the USA. Special attention was given to determining the perceptions farmers have and the barriers they face. Jenkins et al. (2018) investigated farmers' adoption decisions for orange-fleshed sweet potatoes in Mozambique. Mbosso et al. (2015) investigated the factors that influence farmers' attitudes towards a kernel extracting machine in Cameroon.

Unlike the previous research on adoption of innovations, it is currently not feasible to investigate farmers' adoption decisions, perceptions or attitudes regarding IWS. This is because IWS are neither readily available nor understood by farmers. In fact, there is currently very limited information regarding IWS as a crop and soil health promoter (apart from e.g. Debode et al., 2016; Kebli and Sinaj, 2017). Especially limited is information that is tailored for briefing farmers. To address this information gap, this research generates IWS information to specifically address the first stage (the knowledge stage) of the five-stage IDP. According to Rogers (2003) 'Knowledge occurs when an individual (or other decision-making unit) is exposed to an innovation's existence and gains an understanding of how it functions.' Rogers specifies that there are three types of knowledge individuals acquire to learn about an innovation (Table 1).

Awareness, how-to, and principles knowledge regarding IWS as a crop and soil health promoter is limited. The objective of this research is to investigate experts' knowledge of the characteristics and application of IWS as a crop and soil health promoter. Fulfilling this objective will be useful to: (1) assemble a practical and descriptive overview of IWS as a crop and soil health promoter, which can serve as a tool to inform farmers and stakeholders (e.g. consumers and policy makers); and (2) if perceived favourably by farmers, may aid in the uptake of IWS thus progressing towards circular agriculture.

One of the world-leading nations in insect production is the Netherlands, which holds two of the world's largest production facilities and is a driver of developing innovative production-upscaling technologies (RDA, 2018). This research therefore focuses specifically on the application of IWS on Dutch arable farms.

\section{Materials and methods}

Experts with knowledge of IWS and its potential application on Dutch arable farms participated in this research. To elicit experts' knowledge regarding the application of IWS as a crop and soil health promoter on arable farms, a two step-approach was used (Figure 1). First, interviews were conducted to gain insight into the range and diversity of experts' opinions regarding various IWS topics. In many cases, experts shared similar opinions. For a few topics,

\section{Table 1. Knowledge types defined by Rogers (2003).}

\begin{tabular}{|c|c|}
\hline Awareness-knowledge & $\begin{array}{l}\text { 'Information that an innovation exists'. } \\
\text { The information should also describe what } \\
\text { the innovation is. }\end{array}$ \\
\hline How-to knowledge & $\begin{array}{l}\text { 'Information necessary to use an innovation } \\
\text { properly'. }\end{array}$ \\
\hline Principles-knowledge & $\begin{array}{l}\text { 'Information dealing with the functioning } \\
\text { principles underlying how an innovation } \\
\text { works'. }\end{array}$ \\
\hline
\end{tabular}




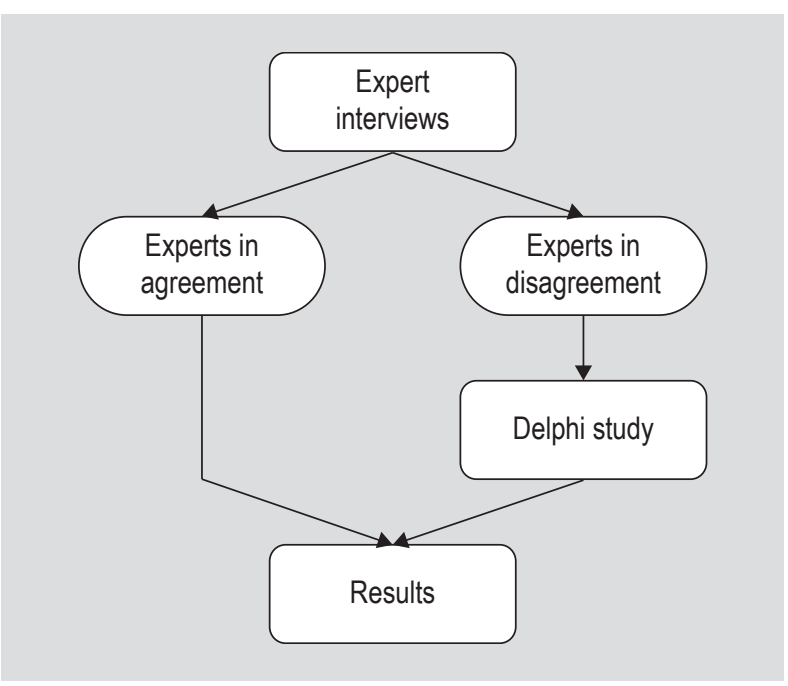

Figure 1. Methodological process.

however, some of the opinions were conflicting. To see whether experts could reach an agreement on these topics, a second step was conducted. In the second step, experts anonymously exchanged thoughts and feedback in an expert consultation method commonly known as a Delphi study.

\section{Expert interviews}

The questions in the interview guide were formulated according to Rogers (2003) to generate awareness-, how-to, and principles-knowledge. Table 2 presents some examples of how each type of knowledge was elicited. A full list can be obtained from the corresponding author upon request.

An extension was made specifically to the definition of awareness knowledge to better align it with the arable farming context. Awareness knowledge was previously defined as information that describes what the innovation is. In the farming context, arguably, the physical appearance of a health promoting innovation is not as important as the expected consequences of using the product. These consequences contribute to the awareness-knowledge of IWS. Thus, to capture expected consequences regarding IWS' performance, studies that investigated attitudes and perceptions of biocontrol agents (Moser et al., 2008) and insects in (food and) feed (Verbeke et al., 2015) were used as input for the interview guide. One example question

\section{Table 2. Example knowledge elicitation questions.}

Awareness-knowledge What is the physical appearance of the
product when it is purchased?
How-to knowledge $\quad$ What steps do farmers need to take to use
the product?

that derived from this addition was, "What are the risks [benefits] for the environment when arable crops and soil are treated with the product?'

Additional questions were included by the researcher to directly address context specific considerations that are relevant for the feasibility of IWS. For example, the following question was included, 'How are the current regulations inhibiting the use of the product as a crop and soil health promoter?. This question is important to answer as legislation in the Netherlands' farming sector becomes increasingly less predictable and farmers try to maintain suitable margins to run their businesses.

Five participants pretested the interview guide following the cognitive interview approach as described by Willis (2005). Participants of the cognitive interviews were selected using convenience sampling based on their experience in crop and soil protection. Improvements were made to the interview guide based on the participants' feedback (see Supplementary Material S1 for the interview guide).

In the current study, an IWS expert was defined as someone who was either: (1) conducting research using IWS; (2) familiar with the preliminary research of IWS and was able to conceptualise its application for Dutch arable farmers; or (3) able to conceptualise the regulatory context that could develop in response to IWS. Six IWS experts participated in one-hour, face-to-face interviews, which took place between May and June 2019. These six participating experts did not overlap with the five who pretested the interview guide.

The interviews were analysed using content analysis (Gray, 2004). First, opinions were organised into subcategories within each interview question. Then sub categories were created as various topics emerged. For example, the question 'What steps do farmers take to use the product?' resulted in sub categories including: how often it is applied and how it is stored. Sub categories were evaluated based on how many participants discussed them and how diverse the opinions were in each. Only the sub categories that contained conflicting expert opinions were tested in the Delphi study.

\section{Delphi study}

A Delphi study was conducted to clarify the conflicting findings in the expert interviews. A Delphi study is a structured group communication process in which data are collected from experts in several subsequent rounds with the aim of facilitating the experts to come to an agreement on a particular topic (Dalkey and Helmer, 1963; Linstone and Turoff, 1975). A Delphi study consists of at least two rounds of data collection. In the first round experts give their anonymous and independent opinion on various aspects of the topic of interest, usually by means of a survey. 
Results are summarised by the study moderator and fed back to the experts. Based on this feedback experts are able to reconsider and change their opinion in the next round of surveys.

Experts invited to participate in the Delphi study included the six experts who participated in the expert interviews and those who they proposed as suitable experts at the end of the interviews. In total, fifteen experts participated in the first round of the Delphi study. Participating experts came from sectors including: academia, governmental agencies, insect and seed producers, and agricultural product developers. Their expertise included among others: microbiomes, microbial and terrestrial ecology, entomology, economics, insect rearing, soil, plants, seeds, and policy.

For the first round of the Delphi study, a survey was developed which included thirteen statements about IWS based on the conflicting opinions from the expert interviews. The survey was pre-tested by three researchers (not part of the 15 experts who participated in the Delphi study) from Wageningen University who gave feedback on its design and the formulation of the statements. In the improved version of the survey, experts were asked to rate to what extent they agreed with the statements. Ratings were made on a scale from 1 (strongly disagree) to 7 (strongly agree). A 'don't know' option was present for experts who wanted to opt out of rating any of the statements. In addition to rating each statement, experts were encouraged to explain their ratings.

The survey developed for the second round of the Delphi study was similar to the first round. Experts were asked to rate the same statements on the same scale. However, this time each statement was provided with a summary of the results from the previous round. This summary consisted of three parts: (1) the expert's own rating of the statement in the previous round; (2) a histogram, showing the distribution of the ratings across the seven points of the scale; and (3) the explanations experts gave for their ratings (anonymised). That way, each expert was able to read the summary and decide whether to modify his/her own rating. Figure 2 shows an example summary of the feedback for one of the statements. Note that the explanations given by experts are not pictured in Figure 2, which were presented in the actual surveys just after the histogram.

The survey for the third (and final) round followed the same set-up and procedure as the second round. Five statements were not presented again because a sufficient level of agreement was achieved for two statements and because ratings remained virtually unchanged (plateaued) for three statements.

All surveys were developed using the online survey platform Qualtrics (http://www.qualtrics.com). Rounds 1, 2 and 3

In Round 2, you stated to what extent you agree or disagree with the following statement about insect waste streams (IWS):

IWS will fully replace artificial fertilizers.

You gave the following answer: neither agree nor disagree.

The graph below shows the answers given by all participating experts.

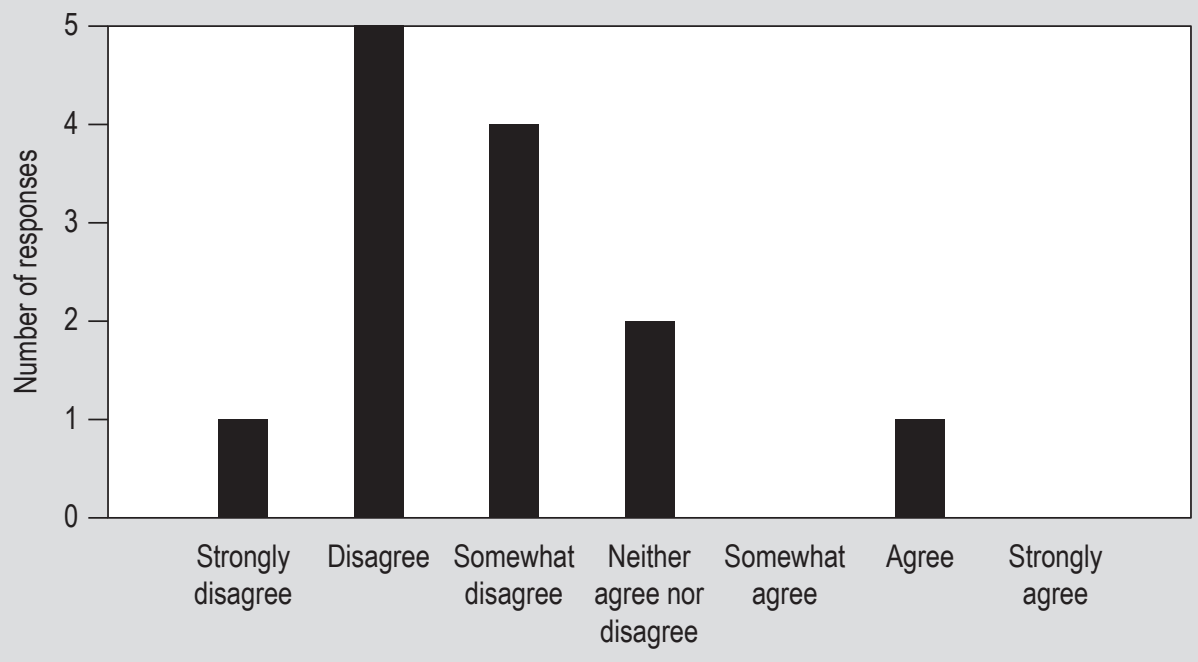

Figure 2. Example quantitative feedback. 
took place between September and October 2019. Round 1 surveys were administered during an individual face-to-face meeting. Because the number of experts was small enough, visiting each expert in the first round was ideal to encourage their participation in subsequent rounds. Each meeting was scheduled for 45 minutes. The surveys for rounds 2 and 3 were sent to participants via email.

To estimate the level of agreement among experts on each statement, the strict agreement (SA) index (Meijering et al., 2013) was calculated using the statistical data-analysis program R (R Core Team, 2019). The SA expresses the number of agreeing expert pairs as a proportion of the total number of possible expert pairs. In the current study, two experts were regarded as being in agreement when they rated a statement using the same point or adjacent points on the scale. For example, on the scale of 1 (strongly disagree) to 7 (strongly agree), rating pairs of 1-1 and 1-2 were both regarded as being in agreement. An exception was made with regards to the mid-point of the scale (4) as it was labelled in the survey as 'neither agree nor disagree'. Arguably, neither ratings of 3 (somewhat disagree) nor 5 (somewhat agree) are in agreeance with 4 . Thus, in the calculation of the SA, the following pairs of ratings were regarded as being in agreement: 1-1, 1-2, 2-2, 2-3, 3-3, 4-4, 5-5, 5-6, 6-6, 6-7, 7-7. For each statement, the SA was calculated by dividing the number of agreeing expert pairs by the total number of possible expert pairs. In theory the SA can take on values between 0 (none of the experts agree with each other) and 1 (all experts agree with each other). In the current study an SA greater than 0.7 was regarded as a sufficient level of agreement among experts as it indicates that $70 \%$ of all expert pairs agreed on the rating of a statement.

Explanations provided by experts in the final rounds underwent a content analysis. This was performed by summarising the explanations making similar arguments, to reduce the feedback. Explanations that were different from any other explanation were summarised and captured in the results. Any explanation that was deemed unclear by the first author was excluded from the results.

\section{Results}

\section{Interview results}

Table 3 shows experts' opinions regarding the awareness knowledge (i.e. physical appearance, anticipated consequences, and policy) of IWS that farmers require. Opinions mentioned by three or more experts were included in Table 3.

According to the experts, IWS could be sold in various forms (i.e. dry granulate, seed coating, and biodegradable seedling cup). Expected benefits of using IWS include the reduced use of harmful chemicals, thus reduced residues on crops and improved yields on unproductive soils. IWS are expected to be more rain resistant, provide organic matter and nutrients to soil, and provide protection for young plants. Some anticipated risks of using IWS include the misuse (e.g. over application) of IWS which can harm production and possible allergic reactions by farmers with insect allergies. Effects on consumer health have not been researched. Until proven otherwise, there could be a risk to consumers.

Table 4 shows experts' opinions regarding the how-to knowledge of IWS farmers require. Opinions mentioned by two or more experts were included in the table.

Experts expected that IWS need to be purchased annually. No other investments need to be made to make use of IWS as the various forms of IWS products are expected to be compatible with existing machinery. IWS should be applied precisely around the roots of seedlings or seeds at the time of planting. No additional labour for applying IWS is expected. Storage requirements and shelf life are expected to be comparable to existing product alternatives.

Table 5 shows experts' opinions regarding the principles knowledge of IWS farmers require. Opinions mentioned by two or more experts were included in the table.

Experts indicated that chitin within the moulted insect skins acts as a substrate for specific soil-dwelling microbes. The presence of these microbes creates a favourable environment for the plant, as they promote the plant's nutrient uptake and resistance against pests and diseases. This process thus promotes the health of crops and soil.

Table 6 presents the topics where mismatches were identified amongst expert opinions on the awareness, howto knowledge, and principles knowledge. An example of identified conflicting opinions can be illustrated using the topic: 'expected effect of IWS in end quality/aesthetics of the end (e.g. vegetable) product'. Some experts gave opinions that IWS would reduce the end product quality and others expected no change.

Based on the topics in Table 6, statements were translated and presented to experts in a Delphi study to find out to what extent they were able to reach an agreement. The numbers in the right most column of Table 6 link the identified conflicting topics to the translated Delphi statements (presented in Table 7). For example, the first conflicting topic in Table 6 was translated into Delphi statement 1 in Table 7. 


\section{K.L. Torgerson et al.}

Table 3. Experts' opinions regarding 'awareness knowledge' of insect waste streams (IWS) (number of experts that expressed the opinion).

\begin{tabular}{|c|c|}
\hline Physical appearance of IWS & $\begin{array}{l}\text { The combined form of these components will be sold as a dry granulate (also described as a highly } \\
\text { concentrated compost), a seed coating, or an IWS-impregnated biodegradable cup that contains seedlings. (6) } \\
\text { IWS are made of the moulted skins (exuviae), manure and undigested feed of insects. (3) }\end{array}$ \\
\hline Environmental consequences & $\begin{array}{l}\text { Indirect benefits of IWS is the reduction of biocides, and thus no build up and negative effects of harmful } \\
\text { chemicals in the soil. (3) } \\
\text { IWS are expected to reduce the amount of chemical residues on crops by reducing the need for spraying. (5) }\end{array}$ \\
\hline Marketing consequences & $\begin{array}{l}\text { IWS are expected to qualify for organic certification. (4) } \\
\text { Using IWS poses no foreseeable marketing risks. (3) } \\
\text { Using IWS poses no foreseeable exporting risks for the end product. (4) }\end{array}$ \\
\hline Consumer health consequences & Experts were able to come up with diverse though highly unlikely risks to consumer health. (6) \\
\hline Farm production consequences & $\begin{array}{l}\text { Improved yields and reduced plant loss are expected, especially on soils that are not very productive. (6) } \\
\text { IWS is less weather sensitive compared to biocides or artificial fertilisers. (4) } \\
\text { IWS supplements but will not replace organic fertilisers. (4) } \\
\text { IWS increase organic matter build up in the soil. (4) } \\
\text { IWS function as a natural fertiliser by providing nutrients to the soil. (4) } \\
\text { IWS induce a plants' systemic resistance by functioning as a biocontrol against pathogenic soil borne } \\
\text { organisms, harmful fungus, and natural enemy insects. (4) } \\
\text { There are no economic incentives used to promote the use of IWS. (3) } \\
\text { An overapplication of IWS can be harmful to plants. For instance, it could result in Nitrogen leaching (4). }\end{array}$ \\
\hline Farmer health consequences & $\begin{array}{l}\text { IWS could improve the health of farmers that currently spray their crops, as using IWS should be low risk } \\
\text { itself and would reduce farmers' exposure to higher risk products. (5) } \\
\text { There are no direct health benefits for farmers. (4) } \\
\text { As insect material is often not found in highly concentrated forms like IWS, it may cause reactions for farmers } \\
\text { with allergies to insects. (5) }\end{array}$ \\
\hline External forces supporting IWS use & $\begin{array}{l}\text { Minister supports circular, sustainable agriculture. (3) } \\
\text { There is a societal trend towards supporting increased circularity and decreased use of synthetic biocides. (5) } \\
\text { Farmers face problems of neonics being taken out of the market. (3) }\end{array}$ \\
\hline IWS regulations & $\begin{array}{l}\text { EU is attempting to implement new legislation on registering biostimulant-type products, which IWS would be } \\
\text { subject to if positioned as a biostimulant product. (3) }\end{array}$ \\
\hline & p chitin showed promis \\
\hline
\end{tabular}

Table 4. Experts' opinions regarding 'how-to knowledge' of insect waste streams (IWS) (number of experts that expressed the opinion).

Purchasing IWS
No prior investments are required to use IWS. (3)
IWS should be purchased approximately $1 \times$ per year. (3)
Experts speculated over various sales channels farmers could source IWS from. (3)
IWS should be applied during or shortly after sowing or planting. (3)
Insect waste streams should not be spread over all the field but rather only precisely around the root systems
of the plants. (2)
No additional labour requirements are needed to use IWS. (5)
IWS are to be kept in a dry and relatively cold place, as other plant protection products are normally stored. (5)
Shelf life of IWS is long and comparable to other plant protection products. (3)
IWS will require a mindset change for some farmers to implement them. Instead of seeing pests and
spraying, farmers must have faith that the plant is mobilising defences and he/she should not spray. (2)


Table 5. Experts' opinions regarding 'principles knowledge' of insect waste streams (IWS) (number of experts that expressed the opinion).

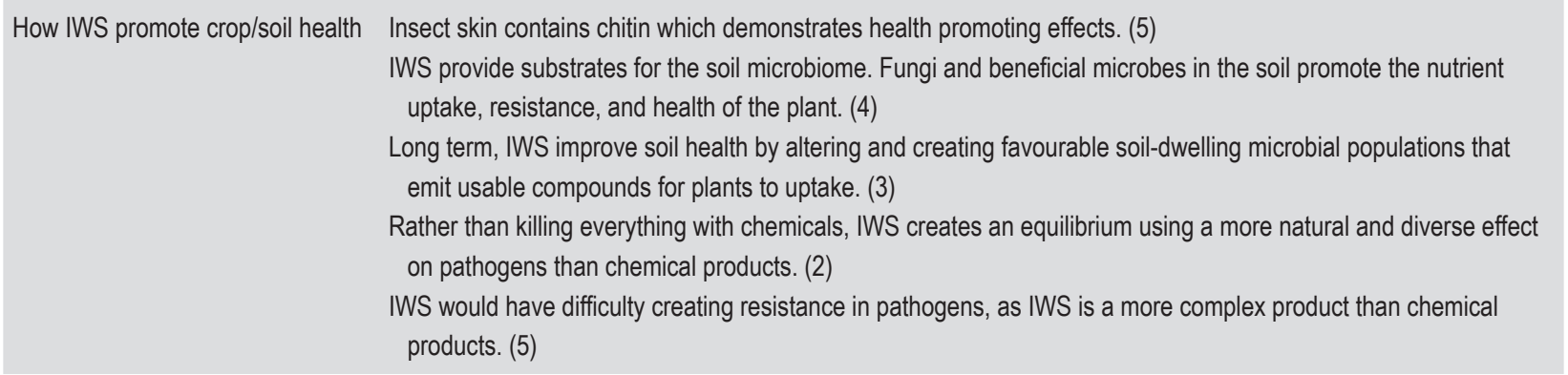

Table 6. Topics regarding insect waste streams (IWS) on which experts had conflicting opinions.

\section{Delphi statement reference no.}

$\begin{array}{lll}\text { Awareness-knowledge } & \text { Expected effect of IWS in end quality/aesthetics of the end (e.g. vegetable) product. } & 1 \\ & \text { Expected cost of IWS compared to currently available products. } & 2,3,4,5 \\ & \text { Expected availability of IWS by } 2020 . & 6 \\ & \text { Extent which IWS replaces the use of artificial fertiliser. } & 7 \\ \text { Extent which IWS replaces the use of chemical sprays \& seed coatings. } & 8,9 \\ \text { How-to knowledge } & \text { Expected dosage of IWS per plant (or hectare). } & 10,11 \\ \text { Principles-knowledge } & \text { Intensiveness of monitoring arable crops and soil treated with IWS. } & 12\end{array}$

\section{Delphi study results}

Fourteen of the fifteen invited experts participated in all three Delphi rounds. Table 7 shows summary statistics for each Delphi round - number of ratings, median, SA, and the distribution of ratings. The number of ratings can be less than the total number of participating experts because the 'don't know' option was available to utilise for any question.

The topic - expected dosage of IWS per plant (or hectare) was removed after the first round due to the large amount of non-response and variation in the few provided answers. Experts were asked to provide an approximate value as $\mathrm{kg} /$ hectare. Only four of fifteen experts responded, and the values ranged from 40 to $5,000 \mathrm{~kg} /$ hectare.

Two of the twelve statements reached the desired SA index threshold of 0.7 . The first was 'IWS will fully replace chemical crop protection sprays (e.g. pesticides)'. This statement reached an SA index of 0.85 with a median rating of 2 or 'disagree.' The second statement was 'Compared to current crop protection practices, in the long term, IWS will result in higher production costs.' This statement reached an SA index of 0.72 with a median rating of 4 or 'neither agree nor disagree.' Both statements fall under awareness knowledge.
The remaining ten statements tested in the Delphi study did not reach the 0.7 threshold. Two reasons that occurred frequently in the feedback of experts throughout the Delphi rounds could explain this outcome. The first recurring argument was that IWS functions only as a fertiliser. In other words, some experts did not agree with or were not familiar with the idea of IWS being used as a crop and soil health promoter. As an example, one expert stated, 'In some answers, people made a connection with pesticides, but that is not the question. IWS is a fertiliser, and will be used in that way ...' Opposing this argument, an expert stated, 'IWS is more than a fertiliser, it is expected to also promote soil microbiota and consequently crop protection.' The second recurring argument was that there is currently too little information and not enough concrete results to draw conclusions.

The following three sections provide an overview of the feedback experts exchanged in the final round of the Delphi study and is presented based on the respective knowledge type.

\section{Expert feedback on awareness-knowledge statements}

Regarding statement 1, residues on the final product would not be expected because IWS should be applied at an early stage (e.g. during planting), thus it would not 
Table 7. Summary statistics for all Delphi study rounds.

\begin{tabular}{|c|c|c|c|c|c|c|c|c|c|c|c|}
\hline \multirow[b]{2}{*}{$\begin{array}{l}\text { Statement: Compared to current crop protection } \\
\text { practices, ... }\end{array}$} & \multicolumn{3}{|c|}{ No. of ratings } & \multicolumn{3}{|c|}{ Median } & \multicolumn{3}{|c|}{ SA index } & \multicolumn{2}{|c|}{$\begin{array}{l}\text { Distribution of ratings } \\
\text { in final round }\end{array}$} \\
\hline & R1 & R2 & R3 & R1 & R2 & R3 & R1 & R2 & R3 & $\begin{array}{l}\text { Disagree } \\
\text { (rated } 1,2 \text {, } \\
\text { or } 3 \text { ) }\end{array}$ & $\begin{array}{l}\text { Agree } \\
\text { (rated } 5,6 \text {, } \\
\text { or } 7 \text { ) }\end{array}$ \\
\hline $\begin{array}{l}\text { 1. when sold in supermarkets, crops (e.g. broccoli) treated } \\
\text { using IWS will have reduced aesthetics (physical } \\
\text { appearance). }\end{array}$ & 12 & 14 & 14 & 2 & 2 & 2 & 0.47 & 0.53 & 0.51 & 11 & 1 \\
\hline $\begin{array}{l}\text { 2. in the short term, IWS will result in higher production } \\
\text { costs. }\end{array}$ & 13 & 13 & 13 & 4 & 4 & 4 & 0.30 & 0.33 & 0.40 & 1 & 5 \\
\hline $\begin{array}{l}\text { 3. in the long term, IWS will result in higher production } \\
\text { costs. }\end{array}$ & 11 & 13 & $\mathrm{~N} / \mathrm{A}$ & 4 & 4 & $\mathrm{~N} / \mathrm{A}$ & 0.49 & 0.72 & $\mathrm{~N} / \mathrm{A}$ & 2 & 0 \\
\hline 4. in the short term, IWS will result in higher yield. & 13 & 13 & 13 & 4 & 4 & 4 & 0.31 & 0.28 & 0.27 & 5 & 5 \\
\hline 5. in the long term, IWS will result in higher yield. & 12 & 13 & N/A & 4.5 & 4 & N/A & 0.32 & 0.33 & N/A & 1 & 6 \\
\hline $\begin{array}{l}\text { 6. assuming (1) IWS are approved by law to sell as a crop } \\
\text { and soil health promoter and (2) there is a large demand } \\
\text { for IWS from high-value crop (e.g. broccoli) farmers in the } \\
\text { Netherlands, there will be enough IWS supply in } 2025 \text { to } \\
\text { satisfy the demand of farmers. }\end{array}$ & 10 & 10 & 8 & 5 & 5 & 4.5 & 0.42 & 0.40 & 0.38 & 1 & 6 \\
\hline 7. IWS will fully replace artificial fertiliser. & 13 & 13 & 14 & 3 & 3 & 2 & 0.39 & 0.54 & 0.54 & 10 & 0 \\
\hline $\begin{array}{l}\text { 8. IWS will fully replace chemical crop protection sprays } \\
\text { (e.g. pesticides). }\end{array}$ & 14 & 13 & N/A & 2 & 2 & N/A & 0.62 & 0.85 & N/A & 12 & 0 \\
\hline 9. IWS will fully replace chemical seed coatings. & 13 & 13 & 13 & 2 & 2 & 2 & 0.55 & 0.62 & 0.59 & 11 & 0 \\
\hline $\begin{array}{l}\text { 10. in conventional farming, farmers will spend more time } \\
\text { monitoring crops and soil treated with IWS. }\end{array}$ & 14 & 14 & 14 & 5 & 5.5 & 5.5 & 0.36 & 0.53 & 0.48 & 2 & 10 \\
\hline $\begin{array}{l}\text { 11. in conventional farming, farmers must obtain additional } \\
\text { knowledge and skills for monitoring crops and soil treated } \\
\text { with IWS. }\end{array}$ & 15 & 14 & N/A & 5 & 5 & $\mathrm{~N} / \mathrm{A}$ & 0.50 & 0.48 & $\mathrm{~N} / \mathrm{A}$ & 3 & 10 \\
\hline 12. IWS will increase the microbial diversity within soil. & 15 & 14 & N/A & 6 & 6 & N/A & 0.51 & 0.51 & $\mathrm{~N} / \mathrm{A}$ & 1 & 11 \\
\hline
\end{tabular}

be present when harvested. Granted, crops treated with IWS should be compared with organic crops, which 'are usually less perfect.' The aesthetics could also be affected in cases of overdosing or due to more insect damage as IWS' efficacy may be lower than conventional PPP. However, in combination with PPP use, such effects would not be anticipated.

In response to statements 2 and 3, higher short-term costs are expected for farmers due to: (1) selling IWS to a niche market and asking higher prices; (2) the lack of IWS available for the market; and (3) more initial monitoring. However, these higher costs are expected to reduce in the long term as more product is made available and less monitoring is required.

In the long run, IWS could be reasonably priced, but it is dependent on many unpredictable factors including: IWS registration costs, cost of producing and processing IWS, the amount and price of reduced inputs (e.g. pesticides), R\&D's trials, and supply and demand. Though some indicated that they did not expect higher costs of production for farmers.

In statements 4 and 5 , lower short-term yields were expected. As IWS is new, farmers need to spend time learning how to work with it, resulting in potentially lower crop yields. Also, optimal and balanced fertilisation practice combined with chemical control is 'unbeatable' by IWS, which is 'unknown, variable, [and has] uncharacterised composition.' IWS' lower yielding effects could be comparable to the bio-farming yields.

Contrary to the aforementioned arguments, the combination of certain unique micro-elements, soil microbial diversity, and improved soil life should result in more stable and (slightly) increasing crop yields over the long term. Notably, the motivation for using IWS should not be to increase yield but to farm more sustainably, as using current conventional crop protection is not sustainable. 
Regarding statement 6, IWS availability will be dependent on: the growth of the insect production sector, how much IWS is needed to apply to be effective, what sort of IWS product is being considered (seed coat versus compost), and the value of crops it is intended to be used on. The insect production sector is expected to grow. Thus, the supply and uptake by farmers is also be expected to grow. Granted this may be true for high value crops such as vegetables, but for crops like maize, potato, wheat, and sugar beet, there will be insufficient supply.

In response to statements 7,8 , and 9, IWS will not fully replace seed coatings, sprays and artificial fertilisers. IWS is amongst a combination of a diverse range of organic farming practices that reduce the use of pesticides and artificial fertiliser. However, fully replacing fertilisers or PPP's was not considered realistic. Specifically regarding the replacement of seed coatings and sprays, IWS only targets a specific group of chitin-degrading microbes. Although this is an important contribution, more protection and solutions are needed against nematodes, insects, and bacteria. IWS alone are not going to be as effective (or direct) as current chemical treatments; it is comparably unstable and unpredictable. In extreme problems and as a last resort, chemical crop protection will still be needed to treat specific pests quickly. Specifically, regarding fertiliser replacement, IWS could in general provide for a nutrient base and therefore reduce the use of artificial fertilisers. However, farmers will also have to use artificial fertilisers to add specific trace elements to create an optimal soilnutrients balance as the nutrient content of IWS is neither balanced nor optimal for full replacement of artificial fertilisers.

\section{Expert feedback on how-to knowledge statements}

Regarding statements 10 and 11, IWS will require more monitoring, at least in the short-run because: (1) it is a new product; (2) its effects are expected to be more variable and thus it is more difficult to judge if it is effectively suppressing pests and diseases compared to chemical treatments; and (3) when part of an integrated pest management approach, it will automatically mean more monitoring than conventional farming. Farmers need extra training in: (1) recognising pest problems in an early stage; (2) understanding soil microbial and soil chemical processes; and (3) accounting for the (non-uniform) nutritional value and less predictable effects (e.g. nutrient release time) of IWS. Opposing these arguments, IWS 'should work according to the recommendations based on research.' Therefore, no additional knowledge or skills would be necessary for farmers.

\section{Experts feedback on principles knowledge statements}

In response to statement 12, IWS will increase soil microbial diversity because of the addition of different sources of food for microbes. In other words, increasing the variety of organic matter in the soil increases microbial diversity. Several experts stressed that they have seen increased soil-microbial diversity in their own research on IWS. However, the longevity of the biodiversity changes should be further investigated. Indirectly, using IWS will reduce the use of pesticides which will 'result in a stimulation of soil microbiota.' In opposition to the aforementioned position, the microbial communities will only face temporary shifts in composition, but there will not be a change in the number of species.

\section{Discussion and conclusions}

This study set out to investigate experts' knowledge of the characteristics and application of IWS as a crop and soil health promoter. In brief, the interviews generated the following IWS knowledge. IWS can potentially be produced as a granulate-type compost, seed coating, or impregnated into a biodegradable seedling cup. Anticipated benefits of using IWS include: the reduced use of harmful chemicals, the addition of organic matter and nutrients to soil, and protection for young plants against pests and disease. The latter two points were similarly concluded by Vickerson et al. (2017) regarding the effects of black soldier fly larvae waste streams on protecting plants from harmful wireworms. Main risks affiliated with using IWS include: the misuse (e.g. over application) of IWS and allergy reactions by farmers allergic to IWS. To use IWS, farmers should apply it next to the roots of each plant during the time of planting. IWS work as a crop and soil health promoter because the chitin, present in the moulted skins, acts as a substrate for beneficial microbes. The microbes emit compounds that promote the plant's health by defending it from pathogens and pests.

From the interviews, topics were identified in which experts did not agree. These topics, further investigated using a Delphi study, resulted in one additional awareness knowledge finding - IWS will not fully replace chemical crop protection sprays (e.g. pesticides). Though many of the tested statements in the Delphi study did not reach the sufficient $0.7 \mathrm{SA}$ index level, several of the topics resulted in a clear direction of expectations. Though doubted by a few of the participating experts, the general expectations are that IWS will not reduce the aesthetics of final products sold in supermarkets; IWS will not fully replace artificial fertilisers nor chemical seed coats; farmers will need to spend more time and acquire more knowledge and skills to monitor crops and soil treated with IWS; IWS will increase the microbial diversity within soil. Though one should not 
conclude that these trends are sufficiently supported by experts, they did result in the support of a great majority.

The results suggest that experts found it easiest to generate principles knowledge; only one topic resulted in some disagreement amongst experts during the interviews, and in the Delphi study, there was a strong trend in the distributions of the statement's ratings. This could be explained in part by either experts conducting their own ongoing research or experts were aware of the results from prior research relating to IWS (Bai, 2015; Debode et al., 2016; Kebli and Sinaj, 2017) and similar materials like shrimp exoskeleton (Benhabiles et al., 2012). Likewise, the results suggest that experts found it more challenging to generate how-to and especially awareness knowledge. Eleven out of the twelve statements tested in the Delphi study were a part of awareness and how-to knowledge. By the end of the Delphi study, five awareness knowledge topics and one how-to knowledge topic showed very little homogeneity in experts' expectations: short and long-term effects on production costs and yields, the availability of IWS by 2025 , and the expected dose of IWS per hectare.

All three types of knowledge are important to understand the innovation; however, awareness knowledge has a particularly crucial role. Rogers (2003) indicates that 'awareness knowledge may motivate an individual to seek a second and third type of knowledge.' If the knowledge generated from this research is presented to farmers, the missing IWS awareness knowledge may result in either farmers' lost interest or false assumptions. In either case, farmers may become demotivated to continue acquiring further IWS-knowledge, ultimately affecting their perceptions of and adoption/rejection decisions regarding IWS.

Although most of the statements in the Delphi study resulted in insufficient levels of agreement, this result is also an important finding. Confucius once said, 'When you know a thing, to hold that you know it; and when you do not know a thing, to allow that you do not know it; this is knowledge.' Having a clear overview of what experts agree on and disagree on is crucial to obtaining a full picture of the available knowledge. Ultimately this research successfully accumulated the first insights into experts' knowledge, expectations, and areas of uncertainty regarding IWS.

As briefly mentioned in section 3.2, the SA index levels below the 0.7 threshold could be attributed to the fundamental disagreement about the functionality of IWS; is IWS only a sort of fertiliser or also functioning as a crop and soil health promoter? This could be explained because the participating experts had different types of expertise. Had the researchers screened the experts for this fundamental functionality belief (that IWS promote the health of crops and soil) it is possible that a higher level of agreement would have been achieved. However, for two reasons, the experts were neither screened nor explicitly informed of the crop and soil health promoting expectations of IWS. The first reason was to allow the experts to express their knowledge unconditionally. Second, the target population of IWS experts in the Netherlands is small; there are simply not many experts affiliated with the topic of IWS.

\section{Policy implications}

Currently, IWS is available on the market as a 'soil improver' but cannot be sold yet (until further legislative support) as, for instance, a biostimulant. The legislative support for applying IWS in practice is lacking in the Netherlands as well as in the EU. IWS currently falls under the EU manure fertilisation regulations. However, alternative registration options would be more suitable. For instance, the EU has a regulation in the pipeline to register biostimulants. Under such registration, IWS can claim to effect plant growth and natural resistance against harmful pests (only) in a general sense. Biostimulant registration would be cheaper, would require less testing, and would be subject to less regulation than biocide registrations. Granted, if registered as a biocide, IWS can claim its effectiveness against specific pathogens or pests, once tested and proven. Registering IWS as either a biostimulant or as a biocide will have enormous consequences on the cost of research and registration, ultimately affecting the price sold to farmers and the feasibility of widespread use in the sector.

Policy makers should recognise the dilemma raised for companies and ultimately farmers by not having a supportive registration process in place that is flexible enough to accommodate biological innovations. Certainly, tests ensuring IWS' effects on food safety, the environment, user's health, etc. must be conducted. However, as society pushes for circularity and sustainability, products embracing such initiatives should be facilitated through the regulatory framework.

\section{Recommendations for future research}

A logical next step for future research would be to track farmers' decision-making process through the IDP. Since IWS are not yet diffused into the market, this case provides a unique opportunity to document farmers' progression through the following stages of their IDP. This expert elicitation can thus serve as a basis of information to disperse to farmers to provide them with at least a basic understanding of how IWS can be applied in practice.

A second suggestion for future (and ongoing) research is to investigate the technical grounds for IWS, especially regarding its effectiveness and practical application on Dutch arable farms. The results of such research should eventually provide evidence to the Delphi statements that 
did not reach a 0.7 SA including: expected short and longterm crop yields, effects on soil microbial diversity, which PPP and fertilisers IWS could potentially substitute, and crop monitoring and dosage recommendations. Once this information is made available, economic feasibility research could estimate farmers' potential production costs and economic benefits when using of IWS.

A third suggestion for future research is a call for further investigations into the knowledge stage of the IDP. This is especially crucial in the agricultural production sector where there is increasingly more demand for more efficient and safer production. Thus, farmers are constantly faced with innovations, just like IWS. The knowledge-generating approach undertaken in this research should be applied to more agricultural innovations and applied to innovations in other sectors.

\section{Acknowledgements}

We would like to acknowledge the following experts, some who participated in the interviews, and all of who gave their valuable opinions in all three rounds of the Delphi study: Marcel Dicke, Anna Kielak, Roy Klein, Gerard Korthals, Henk Lommers, Joop van Loon, Pier Oosterkamp, Jeroen van Schelt, Eric Schmitt, Conor Watson, and Mark van de Wouw, as well as three other experts who preferred to remain anonymous.

Wageningen University's Ethics Committee Social Science (ECSS) approved the conduct of this research. Experts who participated agreed to the research conduct by signing informed consent forms. This work was supported by The Netherlands Organization for Scientific Research NWO [grant number ALWGK.2016.010].

\section{Conflict of interest}

The authors declare that they have no known competing financial interests or personal relationships that could have appeared to influence the work reported in this paper.

\section{Supplementary material}

Supplementary material can be found online at https://doi. org/10.3920/JIFF2020.0095.

Supplementary Material S1. Expert interview guide Insect waste streams to promote the health of arable crops and soil.

\section{References}

Bai, Y., 2015. Ecological functioning of bacterial chitinases in soil. PhD thesis, Leiden University, Leiden, the Netherlands.
Benhabiles, M.S., Salah, R., Lounici, H., Drouiche, N., Goosen, M.F.A. and Mameri, N., 2012. Antibacterial activity of chitin, chitosan and its oligomers prepared from shrimp shell waste. Food Hydrocolloids 29: 48-56. https://doi.org/10.1016/j.foodhyd.2012.02.013

Bodirsky, B.L., Rolinski, S., Biewald, A., Weindl, I., Popp, A. and Lotze-Campen, H., 2015. Global food demand scenarios for the $21^{\text {st }}$ century. PLoS ONE 10: e0139201.

Bortolini, S., Macavei, L.I., Saadoun, J.H., Foca, G., Ulrici, A., Bernini, F., Malferrari, D., Setti, L., Ronga, D. and Maistrello, L., 2020. Hermetia illucens (L.) larvae as chicken manure management tool for circular economy. Journal of Cleaner Production 262: 121289. https://doi. org/10.1016/j.jclepro.2020.121289

Chia, S.Y., Tanga, C.M., Van Loon, J.J.A. and Dicke, M., 2019. Insects for sustainable animal feed: inclusive business models involving smallholder farmers. Current Opinion in Environmental Sustainability 41: 23-30. https://doi.org/10.1016/j.cosust.2019.09.003

Council on Animal Affairs (RDA), 2018. The emerging insect industry; invertebrates as production animals. RDA, The Hague, the Netherlands. Available at: https://english.rda.nl/publications/ publications/2018/09/03/the-emerging-insect-industry

Dalkey, N. and Helmer, O., 1963. An experimental application of the Delphi method to the use of experts. Management Science 9: 458-467.

Debode, J., De Tender, C., Soltaninejad, S., Van Malderghem, C., Haegeman, A., Van der Linden, I., Cottyn, B., Heyndrickx, M. and Maes, M., 2016. Chitin mixed in potting soil alters lettuce growth, the survival of zoonotic bacteria on the leaves and associated rhizosphere microbiology. Frontiers in Microbiology 7: 565. https:// doi.org/10.3389/fmicb.2016.00565

Dulaurent, A.M., Daoulas, G., Faucon, M.P. and Houben, D., 2020. Earthworms (Lumbricus terrestris L.) mediate the fertilizing effect of frass. Agronomy 10: 8. https://doi.org/10.3390/agronomy10060783

Food and Agriculture Organisation (FAO), 2013. The contribution of insects to food security, livelihoods and the environment. FAO, Rome, Italy.

International Platform of Insects for Food and Feed (IPIFF), 2019. The European insect sector today: challenges, opportunities and regulatory landscape. IPIFF vision paper on the future of the insect sector towards 2030. IPIFF, Brussels, Belgium.

Francesca, N., Alfonzo, A., Lo Verde, G., Settanni, L., Sinacori, M., Lucido, P. and Moschetti, G., 2015. Biological activity of Bacillus spp. evaluated on eggs and larvae of red palm weevil Rhynchophorus ferrugineus. Annals of Microbiology 65: 477-485. https://doi. org/10.1007/s13213-014-0881-4

Gadhave, K.R., Finch, P., Gibson, T.M. and Gange, A.C., 2016. Plant growth-promoting Bacillus suppress Brevicoryne brassicae field infestation and trigger density-dependent and density-independent natural enemy responses. Journal of Pest Science 89: 985-992. https://doi.org/10.1007/s10340-015-0721-8

Gadhave, K.R. and Gange, A.C., 2016. Plant-associated Bacillus spp. alter life-history traits of the specialist insect Brevicoryne brassicae L. Agricultural and Forest Entomology 18: 35-42. https:// doi.org/10.1111/afe.12131 


\section{K.L. Torgerson et al.}

Goldberger, J.R., Jones, R.E., Miles, C.A., Wallace, R.W. and Inglis, D.A., 2013. Barriers and bridges to the adoption of biodegradable plastic mulches for US specialty crop production. Renewable Agriculture and Food Systems 30: 143-153. https://doi.org/10.1017/ S1742170513000276

Gray, D.E., 2004. Doing research in the real world. Sage Publications, London, UK.

Houben, D., Daoulas, G., Faucon, M.-P. and Dulaurent, A.-M.m., 2020. Potential use of mealworm frass as a fertilizer: impact on crop growth and soil properties. Scientific Reports 4659: 1-9. https:// doi.org/10.1038/s41598-020-61765-x

Jenkins, M., Shanks, C.B., Brouwer, R. and Houghtaling, B., 2018. Factors affecting farmers' willingness and ability to adopt and retain vitamin A-rich varieties of orange-fleshed sweet potato in Mozambique. Food Security 10: 1501-1519. https://doi.org/10.1007/ s12571-018-0845-9

Kebli, H. and Sinaj, S., 2017. Agronomic potential of a natural fertiliser based on fly larvae frass. Agrarforschung Schweiz 8: 88-95.

Linstone, H.A. and Turoff, M., 1975. The Delphi method: techniques and applications. Addison-Wesley, Reading, MA, USA.

Lugtenberg, B. and Kamilova, F., 2009. Plant-growth-promoting rhizobacteria. Annual Review of Microbioly 63: 541-556. https:// doi.org/10.1146/annurev.micro.62.081307.162918

Mbosso, C., Degrande, A., Villamor, G.B., Van Damme, P., Tchoundjeu, Z. and Tsafack, S., 2015. Factors affecting the adoption of agricultural innovation: the case of a Ricinodendron heudelotii kernel extraction machine in southern Cameroon. Agroforestry Systems 89: 799-811. https://doi.org/10.1007/s10457-015-9813-y

Meijering, J.V., Kampen, J.K. and Tobi, H., 2013. Quantifying the development of agreement among experts in Delphi studies. Technological Forecasting and Social Change 80: 1607-1614. https:// doi.org/10.1016/j.techfore.2013.01.003

Moser, R., Pertot, I., Elad, Y. and Raffaelli, R., 2008. Farmers' attitudes toward the use of biocontrol agents in IPM strawberry production in three countries. Biological Control 47: 125-132. https://doi. org/10.1016/j.biocontrol.2008.07.012

Oonincx, D.G.A.B., Van Itterbeeck, J., Heetkamp, M.J.W., Van den Brand, H., Van Loon, J.J.A. and Van Huis, A., 2010. An exploration on greenhouse gas and ammonia production by insect species suitable for animal or human consumption. PLoS ONE 5: e14445. https://doi.org/10.1371/journal.pone.0014445

Poveda, J., Jiménez-Gómez, A., Saati-Santamaría, Z., UsateguiMartín, R., Rivas, R. and García-Fraile, P., 2019. Mealworm frass as a potential biofertilizer and abiotic stress tolerance-inductor in plants. Applied Soil Ecology 142: 110-122. https://doi.org/10.1016/j. apsoil.2019.04.016
Quilliam, R.S., Nuku-Adeku, C., Maquart, P., Little, D., Newton, R. and Murray, F., 2020. Integrating insect frass biofertilisers into sustainable peri-urban agro-food systems. Journal of Insects as Food and Feed 6: 315-322. https://doi.org/10.3920/JIFF2019.0049

R Core Team, 2019. R: a language and environment for statistical computing. R Foundation for Statistical Computing, Vienna, Austria. Available at: https://www.R-project.org/

Rijksoverheid, 2019. Omslag naar duurzame en sterke landbouw definitief ingezet. Rijksoverheid, The Hague, the Netherlands. Available at: https://tinyurl.com/y6qhl864.

Rogers, E.M., 2003. Diffusion of innovations. Free Press, New York, NY, USA.

Sharma, A., Thakur, D.R., Kanwar, S. and Chandla, V.K., 2013. Diversity of entomopathogenic bacteria associated with the white grub, Brahmina coriacea. Journal of Pest Science 86: 261-273. https:// doi.org/10.1007/s10340-012-0459-5

Steinfeld, H. and Food and Agriculture Organisation, 2006. Livestock's long shadow: environmental issues and options. FAO, Rome, Italy.

Temple, W.D., Radley, R., Baker-French, J. and Richardson, F., 2013. Use of Enterra natural fertilizer (black soldier fly larvae digestate) as a soil amendment. Enterra Feed Corporation, Vancouver, Canada, 34 pp. Available at: https://tinyurl.com/y59vpc5y.

Thornton, P.K., 2010. Livestock production: recent trends, future prospects. Philosophical Transactions of the Royal Society B 365: 2853-2867. https://doi.org/10.1098/rstb.2010.0134

United Nations, 2018. SDG indicators. United Nations, New York, NY, USA. Available at: https://unstats.un.org/sdgs/ metadata? Text $=\&$ Goal $=12 \&$ Target

Van Huis, A., 2013. Potential of insects as food and feed in assuring food security. Annual Review of Entomology 58: 563-583. https:// doi.org/10.1146/annurev-ento-120811-153704

Verbeke, W., Spranghers, T., De Clercq, P., De Smet, S., Sas, B. and Eeckhout, M., 2015. Insects in animal feed: acceptance and its determinants among farmers, agriculture sector stakeholders and citizens. Animal Feed Science and Technology 204: 72-87.

Vickerson, A., Radley, R., Marchant, B., Kaulfuss, O. and Kabaluk, T., 2017. Hermetia illucens frass production and use in plant nutrition and pest management. Google Patents WO2015013826A1. Available at: https://patents.google.com/patent/WO2015013826A1/en

Willis, G.B., 2005. Cognitive interviewing: a tool for improving questionnaire design. Sage, Thousand Oaks, CA, USA. 